\title{
ERRATUM
}

\section{Erratum to: Optical studies of electrodeposited ZnCuTe ternary nanowire arrays}

\author{
Suresh Kumar $\cdot$ Anil Vohra $\cdot$ S. K. Chakarvarti
}

Published online: 24 June 2012

(C) Springer Science+Business Media, LLC 2012

\section{Erratum to: J Mater Sci: Mater Electron} DOI 10.1007/s10854-012-0664-2

In the online version of paper, the $\mathrm{x}$-axis of the Fig. 3 and its caption were given incorrectly by mistake. The correct version of Fig. 3 with its caption is as below:

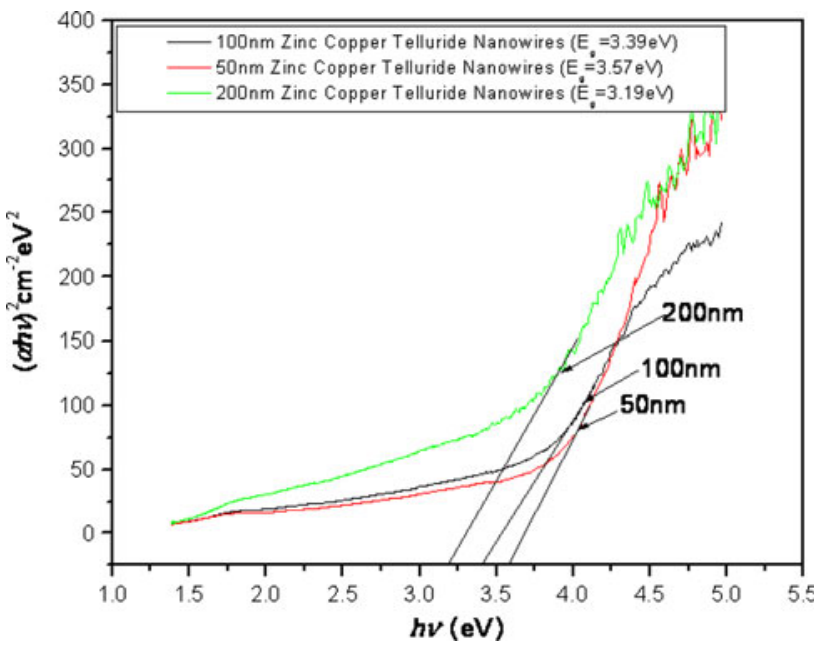

Fig. 3 Plot of $(\alpha h v)^{2}$ versus $h v$ for bandgap calculation of $\mathrm{ZnCuTe}$ nanowires of diameters 200, 100 and $50 \mathrm{~nm}$

The online version of the original article can be found under doi:10.1007/s10854-012-0664-2.

S. Kumar $(\bowtie) \cdot$ A. Vohra

Department of Electronic Science, Kurukshetra University,

Kurukshetra 136119, India

e-mail: sawan2k2@yahoo.co.in

S. K. Chakarvarti

Centre for R\&D, Manav Rachna International University

(MRIU), Faridabad 121004, India 